\title{
Combined Thyroxine and Triiodothyronine for Thyroid Replacement Therapy
}

\author{
SELWYN TAYLOR,* M.D., M.CH., F.R.C.s. ; M. KAPUR, † M.B., B.S., F.R.C.s. ; ROSS ADIE, $\ddagger$ M.B., B.S., F.R.C.S.
}

Cummary: Tablets containing $50 \mu \mathrm{g}$. of thyroxine and $15 \mu \mathrm{g}$. of triiodothyronine have been used to treat patients with hypothyroidism of varied aetiology. Following total thyroidectomy a daily dose of three tabletsthat is, $150 \mu \mathrm{g}$. of thyroxine and $45 \mu \mathrm{g}$. of triiodothyronine -maintained patients in a euthyroid state and produced a protein-bound iodine level within the normal range. The preparation is preferable to dried thyroid because of uniformity of activity and speed of action, and when the patient is clinically euthyroid the P.B.I. falls within the normal range.

\section{Introduction}

Dried thyroid is unsatisfactory for replacement therapy since it varies so much in its content of metabolically active thyroid hormones. Pileggi et al. (1965) showed that, depending on the manufacturer and type of animal gland used the ratio of thyroxine (T4) to triiodothyronine (T3) may vary from unity to three. When pure L-thyroxine (T4) is used as the sole replacement therapy about $0.3 \mu \mathrm{g}$. is required daily and the resulting level of protein-bound iodine (P.B.I.) is well above the normal range of $4-8 \mathrm{mg} . / 100 \mathrm{ml}$. seen in health. If Ltriiodothyronine (T3) is used in a dose of $90 \mu \mathrm{g}$. a day in order to make the patient euthyroid, the P.B.I. falls well below normal. Since we have been recommending therapy with a T4/T3 mixture (Taylor, 1961) we have tried varying combinations of the two hormones, and record our findings here.

\section{Methods and Materials}

All patients who had undergone thyroidectomy for nodular goitre were assessed clinically in the postoperative phase and the P.B.I. was determined. They were then given replacement therapy with the T4/T3 mixture until they appeared clinically to be euthyroid, when the P.B.I. was again determined. The criteria of thyroid function assessed in the outpatient clinic were body weight, pulse rate, skin quality, and sensitivity to cold, supplemented by measurement of the relaxation time of the Achilles tendon. A second group of patients who had undergone total thyroidectomy for thyroid cancer were given replacement therapy in like manner, and this proved particularly important in finding the amount of hormone necessary to replace the normal daily secretion. As each tablet contained what was considered to be equivalent to a 1-gr. (60 mg.) tablet of dried thyroid or $100 \mu \mathrm{g}$. of $\mathrm{T} 4$, one to three tablets were prescribed each morning according to the amount required to make the patient feel completely well. Most of the patients had previously taken dried thyroid or thyroxine, and some of them volunteered the information that they felt better on the T4/T3 mixture, increased energy being the usual comment. When a sudden change to tablets containing T3 was made some patients complained of restlessness, nervousness, insomnia, and palpitations. These passed off in about seven days but if the change was made gradually they did not occur. The converse was also true, and patients who were put back on pure thyroxine tablets often remarked on their lack of energy or that they did not feel so

* Dean, Royal Postgraduate Medical School, Hammersmith Hospital, London W.12.

† Present address: All India Institute of Medical Sciences, New Delhi, India.

¥ Present address: Harrogate and District General Hospital, Harrogate, Yorks. well. Clinically, the rapid subjective improvement due to the $\mathrm{T} 3$ in the tablets encouraged some patients previously on T4 replacement to continue with therapy. It would appear unlikely from our clinical observations that $\mathrm{T} 3$ is formed in significant amounts from $\mathrm{T} 4$ in the body (Braverman and Ingbar, 1969).

\section{Results}

In 1960 we started giving a mixture with a ratio of T4:T3 of 90:10, and for convenience in prescribing each tablet was formulated to be metabolically equivalent to $1 \mathrm{gr}$. $(60 \mathrm{mg}$.) of dried thyroid. This resulted in a high P.B.I. when patients were euthyroid, and the ratio was therefore subsequently changed to $80: 20$. The lowering of the P.B.I. that accompanied this change is shown in Fig. 1. We have now found that a mixture containing $50 \mu \mathrm{g}$. of $\mathrm{T} 4$ and $15 \mu \mathrm{g}$. of $\mathrm{T} 3$ provides excellent replacement, while at the same time the P.B.I. in those patients who have undergone total thyroidectomy falls well within the normal range for our laboratory (Figs. 1 and 2).

\section{Discussion}

Wool and Selenkow (1965) reported on a somewhat similar combination of T4 and T3 and its effect on the P.B.I. and we would confirm that the T3 provides the major part of the metabolic stimulus while the T4 is responsible for the rise in the P.B.I. It has also to be remembered that the T3 will cause a fall in the serum P.B.I. as demonstrated by Farmer et al. (1969), and this in part accounts for what may seem to be the necessity for a relatively large amount of $\mathrm{T} 3$ in the mixture. It is particularly interesting that the studies of Greer on the regulation of thyroid function in iodine deficiency (Studer and Greer, 1966) showed that in severe iodine defi-
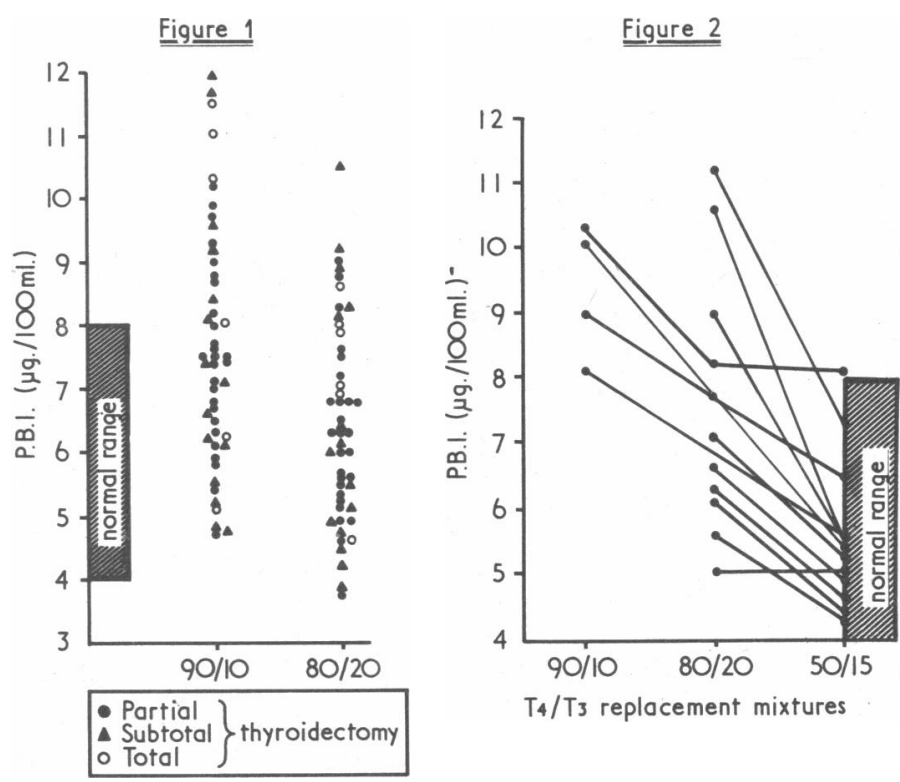

FIG. 1.-Scattergram of P.B.I. determinations in a group of patients receiving T4/T3 mixtures: $90 / 10$ and $80 / 20$.

FIG. 2.-Response of P.B.I. to T4/T3 replacement $(90 / 10,80 / 20$, and $50 / 15)$ in 13 patients who have undergone total thyroidectomy. 
ciency the body becomes much more dependent on T3 and the ratio of $\mathrm{T} 3: \mathrm{T} 4$ rises because biosynthesis of $\mathrm{T} 3$ depends on stimulation by thyroid-stimulating hormone to a much greater extent than does that of T4.

It may be the experience of many clinicians, as it has been ours, that a very small group of patients with hypothyroidism are not entirely well on thyroxine replacement alone. It is particularly for these that we have found the T4/T3 tablet of value. There are two other advantages in the use of a mixture of T4/T3 over T4 alone: the first is that should the patient omit to take the tablets it will be quickly apparent and thus likely to be corrected; the second is that for those patients starting for the first time on thyroid replacement therapy the $\mathrm{T} 3$ content will give a rapid response, which is noticeably lacking for a number of days when only $\mathrm{T} 4$ is prescribed. Such replacement therapy should be started with small doses, especially in the presence of myocardial damage.

Many assistants have taken part in this work during the past eight years. Messrs. Glaxo have provided all the preparations used in these trials.

REFERENCES

Braverman, L. E., and Ingbar, S. H. (1964). New England fournal of Medicine, 270, 439.

Farmer, T. A., Smitherman, T. C., Beschi, R. J., and Pittman, J. A. (1969). Fournal of Clinical Endocrinology and Metabolism, 29, 781 .

Pileggi, V. J., Golub, O. J., and Lee, N. D. (1965). Journal of Clinical Endocrinology and Metabolism, 25, 949.

Studer, H., and Greer, M. A. (1966). Die Regulation der Schliddrüsenfunktion bei fodmangel, p. 505. Bern, Huber.

Taylor, S. (1961). Lancet, 1, 341.

Wool, M. S., and Selenkow, H. A. (1965). Clinical Pharmacology and Therapeutics, 6, 710 .

\section{Gonorrhoea with Skin and Joint Manifestations}

\section{B. WOLFF, ${ }^{*}$ M.B., M.R.C.P.; HELENA V. GOODMAN, † D.M., F.R.C.S., D.PHYS.MED.; J. VAHRMAN, $\ddagger$ M.B., M.R.C.P.ED., C.P.H.}

\begin{abstract}
Cummary : Three cases of gonorrhoea with pyrexia and $\checkmark$ lesions of the skin and joints (benign gonococcaemia) seen in one hospital group in 1969 within four months of one another are described. All three patients improved rapidly with penicillin therapy. This syndrome is commoner than is usually thought. It must therefore be borne in mind when a diagnosis is in doubt in a patient with unusual skin lesions and joint involvement. Thorough bacteriological investigation is necessary before starting treatment. The relevant literature is reviewed.
\end{abstract}

\section{Introduction}

Gonorrhoea with pyrexia and skin and joint lesions may be termed benign gonococcaemia. It is characterized by mildness of general reaction, skin lesions occurring in crops, and joint involvement. It has often been reported in medical journals of the United States. The British Medical Fournal (1964) reviewed an American article by Abu-Nassar, Hill, Fred, and Yow (1963) and discussed its significance. Soon afterwards O'Sullivan (1964) reported two cases admitted to the infectious diseases unit of the Western Hospital, London. No other reports on benign gonococcaemia have appeared in the British medical press in recent years, apart from one from America (Keil, 1938) and another from Sweden (Björnberg and Gisslén, 1966).

Three cases of this disease were recently diagnosed in hospitals of the Chelsea and Kensington Group. This suggests that the condition is commoner than is usually thought. As it does not appear to be well known in Great Britain, these cases merit recording.

\section{Case 1}

A 20-year-old unmarried woman was admitted to St. Mary Abbots Hospital on 15 January, 1969. Her illness began on 12 January with pyrexia, pain and stiffness of the left shoulder, and pain in the left knee. The following day papules appeared on the extremities, while the joints were less painful. On the 14th she

\footnotetext{
* Medical Registrar, St. Mary Abbots Hospital, London W.8. Present Appointment: Lecturer in Physiology, University of London, King's College, London W.C.2

† Consultant in Physical Medicine and Rheumatology, St. Stephen's Hospital, London S.W.10. ‡Consultant Physician, Infectious Diseases, the Western Hospital, Lon-
don S.W.6.
}

experienced pain and swelling of her left ankle, and her general practitioner noted that some skin lesions were haemorrhagic.

On admission to hospital she did not appear ill, her temperature was $98.4^{\circ} \mathrm{F}$. $\left(36.9^{\circ} \mathrm{C}\right.$.), and there were no signs of endocarditis. There was swelling of the left knee and ankle with erythema of the skin over the left medial malleolus. Papules and pustules sparsely scattered over the hands, wrists, and feet were each surrounded by an area of erythema. Some of the pustules on the upper extremities were haemorrhagic. On endoscopic examination a moderate amount of white discharge from the cervix was found. She then admitted that she had been sexually promiscuous.

Neisseria gonorrhoeae was isolated from the cervical swab and from blood taken on 16 January. A urethral swab, fluid from the left knee, and pus from a skin lesion taken that day failed to yield $N$. gonorrhoeae. Specimens of blood taken on 18 and 19 January were sterile.

Her temperature varied from $98.4^{\circ} \mathrm{F}$. $\left(36.9^{\circ} \mathrm{C}\right.$.) to $100^{\circ} \mathrm{F}$. $\left(37.8^{\circ} \mathrm{C}\right.$.) from 15 to 17 January, but then became normal. The left shoulder was already painless on admission, while the symptoms and signs in the left knee and ankle disappeared by the 18th. Her right elbow became painful on the 19th, but remained so for only two days. She was treated with benzylpenicillin intramuscularly six-hourly for two weeks, from 21 January until 4 February. Skin lesions continued to appear, though in diminishing numbers, until 27 January.

On 6 February a cervical swab failed to grow $N$. gonorrhoeae. The patient was discharged on 7 February. Wassermann reaction, gonococcal flocculation test, and cervical cultures were negative on 26 March and 19 May. Cervical culture was again negative on 19 June, and there had been no recurrence of symptoms.

\section{Comment}

This patient showed the features most commonly found in benign gonococcaemia-mildness of the systemic reaction, episodes of pyrexia, a migratory arthritis, and typical skin lesions. She had a sustained pyrexia only during the first three days of her admission. Intermittent or sustained pyrexia is often seen in gonococcaemia with skin lesions (Abu-Nassar et al., 1963; Danielsson and Michaëlsson, 1966; Keiser, Ruben, Wolinski, and Kushner, 1968).

The skin lesions in Case 1 were very similar to those described by Abu-Nassar et al. (1963), with papules rapidly evolving into pustules, scanty peripheral distribution, an erythematous area surrounding each lesion, and the haemorrhagic nature of a few of the pustules. This type of skin lesion should make a physician consider gonococcaemia as a possible diagnosis. The skin lesions of Case 1 on the day after her admission to hospital are shown in Figs 1-3. 